\title{
Could be Reversed the Detrimental Effect of 5-Fluorouracil on Healing of Colonic Anastomosis by Oral Glutamine Supplementation?
}

\author{
Burak Kavlakoglu ${ }^{*}$, Recep Pekcici ${ }^{2}$, Faruk Demir ${ }^{3}$, Halil Yaman ${ }^{4}$ and Sevim Turanli'
}

${ }^{1}$ General Surgeon, Department of General Surgery, Ankara Oncology Training and Research Hospital, Turkey

${ }^{2}$ General Surgeon, Ministry of Health Ankara Training and Research Hospital, Turkey

${ }^{3}$ Histopathologist, Ministry of Health Etlik Zubeyde Hanim Maternity and Womens Health Teaching and Research Hospital, Turkey

${ }^{4}$ Associate Professor of Clinical Biochemistry, Gülhane Military Medical Academy, Turkey

\begin{abstract}
Background/Aim: The anti-neoplastic agents are known to impair tissue healing which may lead to significant post-operative complications, like anastomotic leaks. There has been a number of studies that have shown the protective affects of glutamine on the enteric mucosa. Our study aimed to test whether the addition of enteral glutamine to 5 -fluorouracil $(5 \mathrm{FU})$ used as immediate post-colectomy chemotherapy caused less anastomotic complications compared to 5-FU alone.
\end{abstract}

Materials and methods: Thirty-six female Wistar-Albino rats were initially divided into three groups of twelve rats. The first and the second twelve formed the control (CG) and the 5-FU groups respectively, and were fed on standard laboratory diet and water for seven days. The third group was the Glutamine group (GG) which had oral glutamine supplements in addition to the standard diet. All animals had a laparotomy on day 7 . The left colon was transected and a hand sewn colocolic anastomosis was undertaken (hangi teknik, hand-sewn, single layer, serosubmucosal). All groups were further divided into two subgroups (a total of six groups). The first subgroup in each main group was sacrificed on post-operative day 3 , the remainder were killed on day 7 . Bursting pressures, tissuehydroxyproline and histopathology were compared by Anova test.

Results: Bursting pressure values were significantly reduced by 5FU treatment, both at day 3 and day 7 postoperatively. Glutamine treatment prevented the reduction of bursting pressure in 5FU treated animals, which was not significantly different from animals not treated with $5 \mathrm{FU}$. The lowest mean tissue hydroxyproline levels were found in the 5FU-day 3 \& day 7 groups, histopathology was superior in 5FU-glutamine-day 7 group.

Conclusion: Glutamine neutralised the detrimental affects of 5-FU on tissue healing. This may enable the early inititiation of adjuvant chemotherapy.

Keywords: Glutamine; 5-Fluorouracil; Wound healing; Colonic anastomosis

\section{Introduction}

Colorectal cancer is a common malignancy in most developed countries. In the UK, colorectal cancer is the third most common cause of cancer deaths after lung and prostate cancer in the male, and following breast and lung cancer in the female [1]. In Turkey, colorectal cancer is the third leading cause of cancer death [2]. Metastasis frequently occurs before clinical detection of the primary tumour. Despite the advances in surgical techniques, this characteristic of the malignancy prevents a significant improvement in cure rates for colorectal cancers and almost half of all patients with colorectal cancer will eventually die of recurrent disease. In selected patients, 5-FU based adjuvant chemotherapy has improved survival rates after curative resection [3]. Adjuvant chemotherapy is commonly used in patients with Astler Coller stage B2, C and resectable stage D colorectal cancer. A number of studies showed that the proliferation of cells in the metastatic foci increase after the primary tumor resection. This makes the interval between surgery and the administration of adjuvant chemotherapy critical. According to animal experiments, the most effective reduction of malignant proliferation occurs when the chemotherapeutic agent is administered immediately after tumor removal $[4,5]$.

One of the most important criteria that affects post-operative mortality and morbidity is the integrity of the colonic anastomosis. 5-FU can inhibit the collagen synthesis and when used in the immediate post-operative setting may lead to wound and anastomotic dehiscence [6-11]. This risk often delays the inititiation of the adjuvant chemotherapy until the surgical wounds are healed.

Glutamine is traditionally considered a nonessential amino acid, but appears to be conditionally essential nutrient during injury. It is produced in the body from glutamate and ammonia by the enzyme glutamine synthetase. The process takes place mainly in the skeletal muscle. Glutamine is the most abundant amino acid in plasma and skeletal muscle. The circulating and tissue concentrations of glutamine decrease after injury or surgery $[12,13]$. Glutamine is also the preferred fuel for the intestine, and clinical studies have revealed that both parenteral and enteral glutamine supplementation is beneficial in patients after multiple trauma and surgery $[14,15]$. Utilization of glutamine by the intestine increases after surgery and appears to play a

${ }^{*}$ Corresponding author: Burak Kavlakoglu, General Surgeon, Department of General Surgery, Ankara Oncology Training and Research Hospital, Birlik Mah. 5. Cadde Zirvekent Zambak Sitesi No: 68/4 Cankaya, Ankara, Turkey, Fax: 0090312 2667771; E-mail: bkavlakoglu@hotmail.com

Received December 31, 2011; Accepted March 29, 2012; Published April 02 2012

Citation: Kavlakoglu B, Pekcici R, Demir F, Yaman H, Turanli S (2012) Could be Reversed the Detrimental Effect of 5-Fluorouracil on Healing of Colonic Anastomosis by Oral Glutamine Supplementation? J Cancer Sci Ther 4: 069-074. doi:10.4172/1948-5956.1000113

Copyright: (c) 2012 Kavlakoglu B, et al. This is an open-access article distributed under the terms of the Creative Commons Attribution License, which permits unrestricted use, distribution, and reproduction in any medium, provided the original author and source are credited. 
Citation: Kavlakoglu B, Pekcici R, Demir F, Yaman H, Turanli S (2012) Could be Reversed the Detrimental Effect of 5-Fluorouracil on Healing of Colonic Anastomosis by Oral Glutamine Supplementation? J Cancer Sci Ther 4: 069-074. doi:10.4172/1948-5956.1000113

vital role in mucosal healing [16,17]. In this view, perioperative enteral glutamine supplementation results in improved wound healing and reduces anastomotic complications [18-23].

Our study aimed to find out whether addition of enteral Glutamine supplements made the 5-FU treatment safer in the immediate postoperative period.

\section{Materials and Methods}

Thirty-six female Wistar-Albino rats weighing between 170 and $220 \mathrm{~g}$ were used in this study. All rats were clinically healthy and were fed with standard laboratory food and water. The animals were numbered at the beginning of the study and weighed daily. The study was approved by the local Ethics Committee of Gazi University.

Thirty-six rats were equally divided into six groups. The daily dosage of 5-FU was set at $20 \mathrm{mg} / \mathrm{kg}$ which is the maximum non-lethal dose for rats [24-26]. The glutamine (Resource Glutamine, Nestle) was given as a bolus via an orogastric tube in a dose of $50 \mathrm{mg} / \mathrm{kg} /$ day $[18,19,27]$

The details of the six groups were as follows:

1) Control-day 3 (C-day 3): This group had free access to standard laboratory diet and water in the preoperative 7 days. After the operation, free access to standard laboratory diet and water were continued till the postoperative day 3 . All rats in this group were killed on post-operative day 3 .

2) Control 2 (C-day 7): Identical preoperative feeding regime to C-day 3. The rats were fed for 7 days after the laparotomy and all were sacrificed on day 7 .

3) 5FU-day 3: Preoperative 7 days had free access to a standard laboratory diet and water. 5-FU was administered $20 \mathrm{mg} / \mathrm{kg} /$ day intraperitoneally at the time of the operation and it was repeated intraperitoneally once daily on the first and second postoperative days. Free access to standard laboratory diet and water were continued for the postoperative 3 days. Animals were killed on day 3.

4) 5FU-day 7: Identical to 5FU1 except animals were killed on day 7.

5) 5FU-gutamine-day 3 (5FUG-day 3): Preoperative 7 days $50 \mathrm{mg} /$ kg Glutamine (Resource Glutamine, Nestle) feeding via orogastric tube as well as free access to standard laboratory diet and water. 5 -FU was administered $20 \mathrm{mg} / \mathrm{kg} /$ day intraperitoneally at the time of operation and it was repeated intraperitoneally once daily for the first and second postoperative days. Glutamine feeding $(50 \mathrm{mg} /$ $\mathrm{kg}$ ) via orogastric tube and free access to a standard laboratory diet and tap water were continued for the postoperative 3 days. Animals were killed on day 3.

6) 5FU-glutamine-day 7 (5FUG-day 7): Identical to 5FUG1 except animals were killed on day 7.

\section{Operative Procedure}

All rats were anesthetized with an intramuscular injection of 50 $\mathrm{mg} / \mathrm{kg}$ ketamine hydrochloride and $10 \mathrm{mg} / \mathrm{kg}$ xylazine hydrochloride. Surgical procedures were performed under semi sterile conditions. Laparotomies were performed through midline incisions of approximately $5 \mathrm{~cm}$. The left colon was completely transected approximately $1 \mathrm{~cm}$ proximal to the peritoneal reflection and an end- to-end anastomosis was performed consisting of eight interrupted 6-0 polipropylene sutures (Prolene, Ethicon") (Figure 1). The abdominal layers and skin incision were closed en bloc with a running 3-0 monocryl (Ethicon) suture. Postoperatively, rats in the group of C-day 3, C-day 7, 5FU-day 3 and 5FU-day 7 were allowed free access to tap water and food and libitum and in the group of 5FUG-day 3 and 5FUG-day 7 rats were allowed same diet plus $50 \mathrm{mg} / \mathrm{kg}$ bolus Glutamine feeding via orogastric tube immediately.

\section{End of study procedures}

Groups C-day 3, 5FU-day 3 and 5FUG-day 3 were killed on postoperative day 3 and groups C-day 7, 5FU-day 7 and 5FUG-day 7 were killed on postoperative day 7 . All animals were anesthetized in the same manner and laparotomy was performed via the previous incision scar. All anastomoses and intra-abdominal adhesions were examined in vivo before the resection. Then a $10 \mathrm{~cm}$ segment of the left colon which included the anastomosis was resected. The bursting pressure measurements were performed ex vivo as follows:

\section{Measurement of bursting pressures}

On the back table a $10 \mathrm{Fr}$ catheter was inserted to the proximal part of the colon and fixed with 4/0 silk sutures then connected to the perfusor (B.Braun Perfusor'Space). The distal part of the colon was connected to the arterial line transducer set with a $10 \mathrm{Fr}$ connector. The strength of each anastomosis was assessed by measuring its burst pressure using the perfusor operating at $150 \mathrm{ml} / \mathrm{h}$ with an invasive arterial blood pressure transducer (Datex-Ohmeda Cardiocap $/ 5^{\circ}$ ) and measured systolic pressures were accepted as the bursting pressure $(\mathrm{mmHg})$. The maximum pressure immediately preceding the sudden fall as a result of explosion was recorded as the bursting pressure. Results were recorded with Statistical Package for the Social Sciences version 13.0 software (SPSS, Inc., Chicago, IL, USA).

After measurement of bursting pressures, anastomotic segments of $2 \mathrm{~cm}$ were separated from the specimen, wrapped in aluminium foil, and frozen in liquid nitrogen. Samples were then stored $\left(-20^{\circ} \mathrm{C}\right)$ until the end of the experiment for hydroxyproline measurement. Animals were killed by overdose injection of ketamine hydrochloride $(100 \mathrm{mg} /$ $\mathrm{kg}$ ) and xylazine hydrochlo ride $(20 \mathrm{mg} / \mathrm{kg})$.

\section{Measurement of tissue hydroxyproline content}

Briefly, the tissue specimen was homogenized to a fine solution in cold saline, hydrolyzed in alkali and oxidized with chloramine T. The chromophore was developed with the addition of Ehrlich's aldehyde and the absorbance of the chromophore was measured at $550 \mathrm{~nm}$.

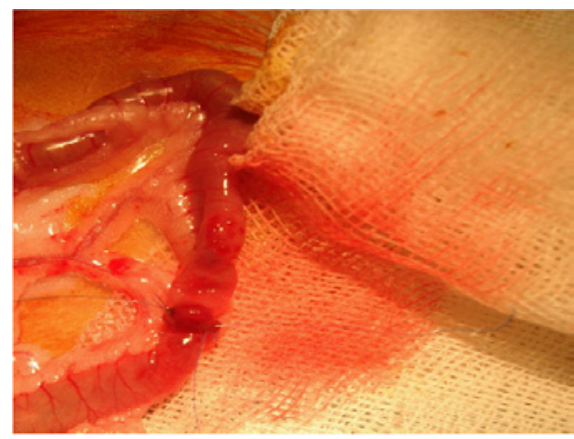

Figure 1: End-to-end left colon anastomosis with eight interrupted 6-0 propylene sutures. 
Citation: Kavlakoglu B, Pekcici R, Demir F, Yaman H, Turanli S (2012) Could be Reversed the Detrimental Effect of 5-Fluorouracil on Healing of Colonic Anastomosis by Oral Glutamine Supplementation? J Cancer Sci Ther 4: 069-074. doi:10.4172/1948-5956.1000113

The concentration of hydroxyproline in each tissue specimen was deduced from a standard calibration curve. Hydroxyproline levels were expressed as micrograms per milligram of tissue [28,29].

\section{Anastomotic Complications and Intra-Abdominal Adhesions}

All anastomoses were examined during the second laparotomy before the bursting pressure measurements. Intra-abdominal adhesions were classified according to the Blauer scoring system $(0=$ no adhesions; 1 = thin or narrow, easily separable adhesions; 2 = thick adhesions, limited to one area; $3=$ thick and widespread adhesions; $4=$ thick and widespread adhesions, plus adhesions of viscera to anterior or posterior abdominal wall) [30,31].

\section{Microscopic Examination}

For histological comparisons, one rat from each group was not subjected to measurement of bursting pressure and hydroxyproline. All tissue specimens were obtained from the anastomosis area and fixed in $10 \%$ buffered formalin, processed by routine protocols for embedding in paraffin wax, and cut into serial $5 \mu$ thick sections by microtome. The sections were stained with haematoxylin and eosin and examined using a photomicroscope (BX50; Olympus, Tokyo, Japan). The accumulation of Polymorphonuclear Cells (PMNs), lymphocytes and macrophages (inflammation); thickness of the wall at the anastomosis relative to the thickness of the normal intestinal wall; submucosalmuscular layer repair; and amounts of necrosis and vascularisation on histopathological examination under light microscopy were scored from 0 to 3 [19].

\section{Statistical Analysis}

Data are expressed as mean $\pm \mathrm{SD}$ for continuous outcomes. Statistical tests were chosen according to the distribution of data. Differences of the mean bursting pressures between the control and the treatment groups were assessed by one-way analysis of variance (ANOVA). The mean hydroxyproline content differences among all six groups were analyzed by one-way ANOVA. When the $\mathrm{p}$ value from ANOVA was significant, post-hoc Tukey HSD multiple comparison tests were performed. Intra-abdominal adhesions were analyzed by Kruskal-Wallis nonparametric test. The value of $p<0.05$ was accepted as significant.

\section{Results}

\section{Complications and weight loss}

No wound complications were observed in the study or control groups and none of the rats died. There were no significant weight loss in the C-day $3 \&$ day 7 and 5FUG-day $3 \&$ day 7 groups, but there were significant weight loss in the 5FU-day 3 and day 7 groups when compared with the respective Control and Glutamine groups. Mean differences of the weight(MDW) until killing day during the study are shown in Table 1.

\section{Anastomotic complications and intra-abdominal adhesions}

No perforation, intra-abdominal abscess, or anastomotic dehiscence was observed except the groups of C-day 3, 5FU-day 3 and 5FU-day 7. Adhesions were scored on a scale of $0-4$ according to Blauer's scoring system and the evaluation of the differences of adhesions between the groups were shown in Table 2.

\section{Bursting site and pressure}

In most animals the bursting site was along the anastomosis line.

\begin{tabular}{|l|c|c|c|}
\hline Groups $(n=6)$ & MDW \pm SD $(g)$ & MDW of C-day3 group \pm SD $(g)$ & $p$ \\
\hline 5FU-day3 & $-7.6 \pm 5.04$ & $14.3 \pm 4.08$ & 0.001 \\
\hline 5 FUG-day3 & $6.0 \pm 4.04$ & $14.3 \pm 4.08$ & 0.014 \\
\hline$p$ & 0.001 & & \\
\hline Groups $(n=6)$ & MDW \pm SD $(g)$ & MDWof C-day7 group \pm SD $(g)$ & $p$ \\
\hline 5FU-day7 & $-10.5 \pm 9.09$ & $34.3 \pm 6.80$ & 0.001 \\
\hline 5FUG-day7 & $15.8 \pm 3.76$ & $34.3 \pm 6.80$ & 0.001 \\
\hline$p$ & 0.001 & & \\
\hline
\end{tabular}

Table 1: Mean differences of the weight among the groups until sacrifice day.

\begin{tabular}{|l|c|c|}
\hline Groups $(\mathrm{n}=6)$ & Mean rank of the intra-abdominal adhesions & $\mathrm{p}$ \\
\hline C-day3 & 4.00 & \\
\hline 5FU-day3 & 15.50 & 0.001 \\
\hline 5FUG-day3 & 9.00 & \\
\hline C-day7 & 3.67 & \\
\hline 5FU-day7 & 15.50 & 0.001 \\
\hline 5FUG-day7 & 9.33 & \\
\hline
\end{tabular}

Table 2: Mean rank of the intra-abdominal adhesions and the $p$ value among the study groups according to the Kruskal Wallis test on sacrifice day 3 and 7 .

Anastomotic ruptures were more common in the C-day 3, 5FU-day 3 and 5FU-day 7 groups than in the C-day 7, 5FUG-day 3 and 5FUGday 7 groups $(\mathrm{p}<0.01)$. The bursting pressure values were lower in the 5FU-day 3 and 5FU-day 7 groups than in the respective control and glutamine groups. The differences of the Mean Bursting Pressures (MBP) between and within the study groups on postoperative day 3 and 7 were significant ( $\mathrm{p}=0.022$ and 0.001 respectively).

According to this result, the corelation between the study groups were calculated with Multiple Comparisons of Tukey test, the difference between the $\mathrm{C} 1$ vs $5 \mathrm{FU}-1$ ( $\mathrm{p}=0.017)$ groups was found significant.

On the other hand, the differences of the MBP between and within the study groups on postoperative day 7 were also found significant ( $\mathrm{p}=0.001$ ). According to this result, the corelation between the study groups were also calculated with Multiple Comparisons of Tukey test, and the differences between the, $5 \mathrm{FU}-2$ vs $\mathrm{C} 2(\mathrm{p}=0.007)$ and $5 \mathrm{FU}-2$ vs 5FU-G2 ( $\mathrm{p}=0.001)$ groups were found significant (Table 3 ).

\section{Tissue hydroxyproline content}

The Mean Tissue Hydroxyproline Content (MTHC) of the colonic anastomosis in the study groups were compared. The lowest MTHC of the colon anastomosis were found in the 5FU-1 and 5FU-2 groups than the respective control and glutamine groups. However, the differences of MTHC of the colon anastomoses between and within the study groups of postoperative day 3 were not found significant $(p=0.334)$. On the other hand, the differences were found significant in the study groups of postoperative day 7 ( $\mathrm{p}=0.001)$.

According to this result, the corelation between the study groups of postoperative day 3 and 7 were calculated with Multiple Comparisons of Tukey test. The differences of the MTHC between the groups of 5FU-G1 vs $5 \mathrm{FU}-1(\mathrm{p}=0.004)$ and $\mathrm{C} 1$ vs $5 \mathrm{FU}-1(\mathrm{p}=0.042)$ were found significant, but $5 \mathrm{FU}-1$ vs $\mathrm{C} 1$ were insignificant. On the other hand, the differences of the MTHC between the groups of 5FU-G2 vs both C2 $(\mathrm{p}=0.002)$ and 5FU-2 ( $\mathrm{p}=0.001)$ were found significant (Table 4$)$.

\section{Histopathological evaluation}

The mucosal epithelium integrity was poor in the 5FU-1 group (Figure 2), but the mucosal epithelium integrity was better in the 5FUG2 group illustrated in (Figure 4). According to the colon anastomosis 
Citation: Kavlakoglu B, Pekcici R, Demir F, Yaman H, Turanli S (2012) Could be Reversed the Detrimental Effect of 5-Fluorouracil on Healing of Colonic Anastomosis by Oral Glutamine Supplementation? J Cancer Sci Ther 4: 069-074. doi:10.4172/1948-5956.1000113

\begin{tabular}{|c|c|c|c|c|c|c|c|}
\hline & $\mathrm{MBP} \pm \mathrm{SD}(\mathrm{mmHg})$ & C-day3 & 5FU-day3 & 5FUG-day3 & C-day7 & 5FU-day7 & 5FUG-day 7 \\
\hline C-day3 & $41.50 \pm 6.31$ & & $p=0.017$ & & & & \\
\hline 5FU-day3 & $20.33 \pm 14.05$ & & & $p=0.282$ & & & \\
\hline 5FUG-day3 & $31.00 \pm 13.05$ & $p=0.293$ & & & & & \\
\hline C-day7 & $179.33 \pm 77.41$ & & & & & $p=0.007$ & \\
\hline 5FU-day7 & $47.00 \pm 37.40$ & & & & & & $p=0.001$ \\
\hline 5FUG-day7 & $215.50 \pm 68.00$ & & & & $p=0.594$ & & \\
\hline
\end{tabular}

Table 3: The differences of mean bursting pressures (MBP) between the groups according to the Multiple Comparisons of Tukey test.

\begin{tabular}{|l|c|c|c|c|c|c|}
\hline & MTHC $\pm S D(\mu \mathrm{mol} / \mathrm{g})$ & C-day3 & 5FU-day3 & 5FUG-day3 & C-day7 & 5FU-day7 \\
\hline C-day3 & $0.375 \pm 0.08$ & & $\mathrm{p}=0.042$ & & \\
\hline 5FU-day3 & $0.207 \pm 0.07$ & & & $\mathrm{p}=0.004$ & \\
\hline 5FUG-day3 & $0.448 \pm 0.14$ & $\mathrm{p}=0.488$ & & & \\
\hline C-day7 & $0.574 \pm 0.07$ & & & \\
\hline 5FU-day7 & $0.353 \pm 0.06$ & & & \\
\hline 5FUG-day7 & $0.859 \pm 0.12$ & & & $p=0.002$ \\
\hline
\end{tabular}

Table 4: The differences of mean tissue hydroxyproline content (MTHC) between the groups according to the Multiple Comparisons of Tukey test.

healing scores, the inflammation, type of the mucosal epithelium, submucosal-muscular healing and necrosis scores of the 5FU-G2 group were found better than 5FU-2 group (Figure 3 ) significantly $(\mathrm{p}=0.01$ ).

\section{Discussion}

Adjuvant chemotherapy after curative resection of colorectal cancer may be beneficial in some patients to reduce the risk of metastasis. However the timing of adjuvant chemotherapy is one

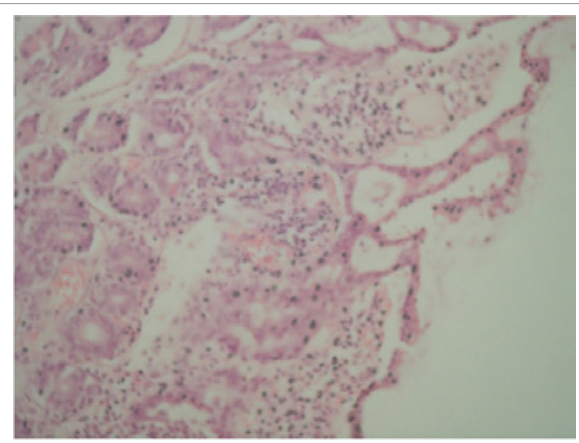

Figure 2: Ch1 Intestinal anastomosis: Mucosal desquamation-mucositis and submucosal lymphocytic infiltration (Haematoxylin and eosin dyes, x20), mucosal regularity was not observed.

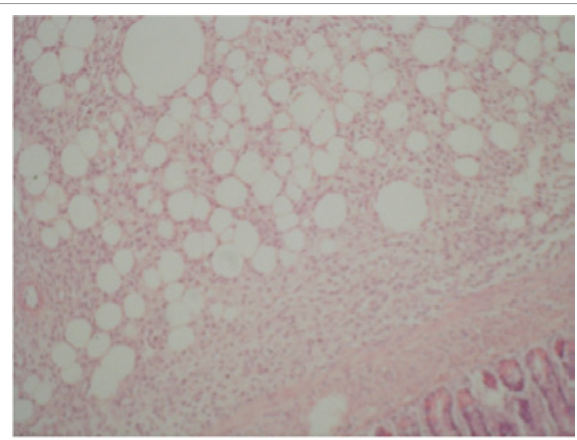

Figure 3: Ch2 Intestinal anastomosis. Submucosal lymphocytic infiltration, fat necrosis and fibroblastic proliferation in the periserosal fatty tissue and serositis (Haematoxylin and eosin dyes, $x 20$ ), poor mucosal healing was observed.

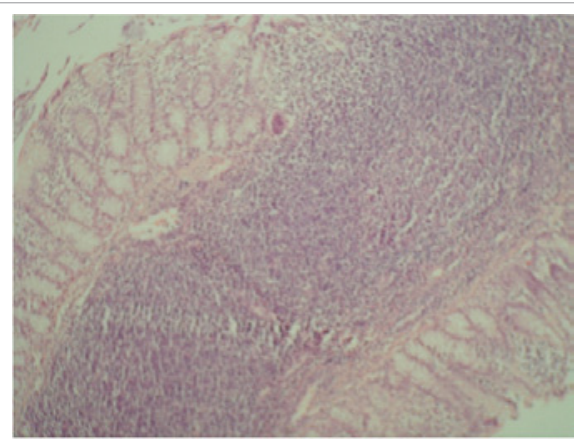

Figure 4: G2 Intestinal Anastomosis: Mucosal lymphocytic infiltration and fibroblastic proliferation in the periserosal fatty tissue (Haematoxylin and eosin dyes, $\mathrm{x} 10)$. Fat necrosis, mucositis and serositis are absent, perfect mucosal healing was observed.

of the most important problems after resection. Perioperative use of chemotherapeutics causes poor wound healing and increases the risk of wound dehiscence because of inhibition of collagen synthesis. Tissue hydroxyproline level is an important parameter in the tissue repair process $[32,33]$. Some studies indicated that 5 -FU decreases the hydroxyproline content in the wounds. In the study of van der Kolk et al. [34], after the 5-FU treatment the anastomotic hydroxyproline content was found lower than the respective controls. In another study, Kuzu et al. [35] demonstrated that, although no significant differences were found in anastomotic burst pressures between the groups, hydroxyproline content were found significantly lower following 5-FU chemotherapy. As a result, adjuvant treatment is usually withheld, until the wound is healed.

Glutamine is the main energy substrate for the enterocytes. In the study of Rouse et al. [36], glutamine was a primary respiratory fuel and also as a necessary substrate for nucleotide synthesis in most dividing cells such as enterocytes. In this study, protecting effect of oral glutamine was also demonstrated in normal tissues and possibly sensitizing tumor cells from chemotherapy-related injury via the effects of oral glutamine on tumor and host glutathione metabolism. In another study Sukhotnik et al. [37] researched the effects of oral glutamine in preventing intestinal mucosal damage caused by Methotrexate (MTX) 
Citation: Kavlakoglu B, Pekcici R, Demir F, Yaman H, Turanli S (2012) Could be Reversed the Detrimental Effect of 5-Fluorouracil on Healing of Colonic Anastomosis by Oral Glutamine Supplementation? J Cancer Sci Ther 4: 069-074. doi:10.4172/1948-5956.1000113

in rats. According to this study, MTX-glutamine in rats indicated better mucosal healing compared to MTX animals. On this basis, we can say perioperative glutamine intake causes improved wound healing and may reduce the risk of wound dehiscence. Gut's glutamine requirement is increased in catabolic states like surgery and immunosuppression. Although, glutamine is not classified as an essential amino acid, some studies emphasized that glutamine was an essential dietary element for the intestinal mucosal proliferation and growth [20]. As shown in our study, glutamine supplementation enhanced the healing of the colonic anastomosis and significantly reduced the negative affects of 5-FU on the healing process. We believe that this improvement can lead to early initiation of adjuvant chemotherapy which will give our patients the best chance in disease free survival.

In view of the administration route of Glutamine, our findings are very much in line with the previous publications that enteric route is both practical and efficient. Demetriades et al. [21], showed the positive affects of early postoperative glutamine enriched enteral feeding. Gokpinar et al. [22] also reported improved anastomotic healing with early enteral nutrition and glutamine enrichment in the postoperative period. In another study, da Costa et al. [23] reported that, total rupture strength and the percent area of mature collagen at the anastomoses sites on postoperative days 3 and 8 were increased by perioperative oral glutamine supplementation. On the contrary, Cihan et al. [38] demonstrated that, under normal conditions there was no beneficial affect on anastomotic bursting pressures with early enteral feeding with glutamine enriched diet.

Through a literature search, we could not identify any other study that that looked into the affects of glutamine supplementation on anastomotic healing in the presence of chemotherapy and this present study is the first one to show that glutamine strongly protects the integrity of anastomoses and levels of tissue hydroxyproline content in the presence of 5-FU .

Postoperative weight loss is an important indicator of nutritional status. Weight loss is also an important side effect of antineoplastic agents. In this study, weight loss was significant in 5-FU treated rats. This weight loss was substantially reduced by oral glutamine therapy. From this point of view, it is assumed that glutamine supported the nutritional status of the animals both in the early phase (postoperative day 3 ) and the late phase of the anastomotic healing (postoperative day 7).

Intra-abdominal adhesions were significantly more common in 5FU-treated animals that were on a normal diet compared to the ones that received glutamine supplementation. This suggested that, glutamine may have some protective effect on adhesion formation if given with 5-FU.

The most important observation in our study was the significant reduction in anastomotic leaks. The leaks only occurred in 5FU treated animals that did not receive any glutamine. In fact, negative effects of 5-FU on anastomotic healing were shown before. Kanellos et al. [39] demonstrated that, the perioperative intraperitoneal administration of 5 -FU inhibits the healing of colonic anastomoses in rats.

In another study, Ersoy et al. [11] showed that bursting pressures of colonic anastomosis in rats that received 5-FU treatment were significantly lower than those of the control animals. Anastomotic leakage was a predicted complication in 5-FU treated animals. Our data suggests that glutamine has a protective effect on tissue healing which almost neutralises the negative affects of 5-FU.
In conclusion, higher bursting pressures in the glutamine groups indicate that glutamine prevents the negative effects of antineoplastic agents on wound healing. Higher tissue hydroxyproline levels and lower inflammation and necrosis scores in the glutamine groups also support this conclusion. Starting from the preoperative and in the early enteral nutrition period, addition of the glutamine to the nutritional intake could be beneficial for the healing of the colonic anastomosis. Perioperative glutamine supplementation can enable the immediate post-operative use of 5-FU in treatment of colorectal cancer.

\section{tement}

Burak Kavlakoglu and other co-authors have no conflict of interest.

\section{References}

1. Rowan S, Brewster D (2005) Studies on Medical and Population Subjects No. 68 Chapter 7: Colorectal. In: Mike Quinn, Helen Wood, Nicola Cooper, Steve Rowan, eds. Cancer Atlas of the United Kingdom and Ireland 1991-2000. National Statistics: 21

2. Ozsoy SA, Ardahan M, Ozmen D (2007) Reliability and validity of the colorecta cancer screening belief scale in Turkey. Cancer Nurs 30: 139-145.

3. Mayer RJ (1991) Systemic therapy for colorectal cancer: an overview. Semin Oncol 18: 62-66.

4. Macdonald JS, Astrow AB (2001) Adjuvant therapy of colon cancer. Semin Oncol 28: 30-40.

5. Sobrero A, Kerr D, Glimelius B, Van Cutsem E, Milano G, et al. (2000) New directions in the treatment of colorectal cancer: a look to the future. Eur J Cancer 36: 559-566.

6. Weiber S, Graf W, Glimelius B, Jiborn H, Påhlman L, et al. (1994) Experimental colonic healing in relation to timing of 5-fluorouracil therapy. Br J Surg 81: 1677 1680 .

7. Weiber S, Graf W, Glimelius B, Jiborn H, Påhlman L, et al. (1994) The effect of 5-fluorouracil on wound healing and collagen synthesis in left colon anastomoses. An experimental study in the rat. Eur Surg Res 26: 173-178.

8. van der Kolk BM, de Man BM, Wobbes T, Hendriks T (1999) Is early post operative treatment with 5 -fluorouracil possible without affecting anastomotic strength in the intestine? Br J Cancer 79: 545-550.

9. Cunliffe WJ, Sugarbaker PH (1989) Gastrointestinal malignancy: rationale for adjuvant therapy using early postoperative intraperitoneal chemotherapy. $\mathrm{Br} \mathrm{J}$ Surg 76: 1082-1090.

10. Fisher B, Gunduz N, Saffer EA (1983) Influence of the interval between primary tumor removal and chemotherapy on kinetics and growth of metastases. Cancer Res 43: 1488-1492.

11. Ersoy E, Akbulut H, Moray G (2009) Effects of oxaliplatin and 5-fluorouracil on the healing of colon anastomoses. Surg Today 39: 38-43.

12. Blomvist BI, Hammarqvist F, von der Decken A, Wernerman J (1993) Glutamine and a-ketoglutarate attenuate the fall in muscle free glutamine concentration after total hip replacement. Clin Nutr 12: 12-13.

13. Parry-Billings M, Baigrie RJ, Lamont PM, Morris PJ, Newsholme EA (1992) Effects of major and minor surgery on plasma glutamine and cytokine levels. Arch Surg 127: 1237-1240.

14. Planas M, Schwartz S, Arbós MA, Farriol M (1993) Plasma glutamine levels in septic patients. JPEN J Parenter Enteral Nutr 17: 299-300.

15. Wernerman J, Hammarkvist F, Ali MR, Vinnars E (1989) Glutamine and ornithine-a-ketoglutarate but not branched-chain amino acids reduce the loss of muscle glutamine after surgical trauma. Metabolism 38: 63-66.

16. Parry-Billings M, Evans J, Calder PC, Newsholme EA (1990) Does glutamine contribute to immunosuppression after major burns? Lancet 336: 523-525

17. Griffiths RD, Jones C, Palmer TE (1997) Six-month outcome of critically ill patients given glutamine-supplemented parenteral nutrition. Nutrition13: 295302

18. Savarese DM, Savy G, Vahdat L, Wischmeyer PE, Corey B (2003) Prevention of chemotherapy and radiation toxicity with glutamine. Cancer Treat Rev 29 501-513. 
Citation: Kavlakoglu B, Pekcici R, Demir F, Yaman H, Turanli S (2012) Could be Reversed the Detrimental Effect of 5-Fluorouracil on Healing of Colonic Anastomosis by Oral Glutamine Supplementation? J Cancer Sci Ther 4: 069-074. doi:10.4172/1948-5956.1000113

19. Güven A, Pehlivan M, Gökpinar I, Gürleyik E, Cam M (2007) Early glutamineenriched enteral feeding facilitates colonic anastomosis healing: light microscopic and immunohistochemical evaluation. Acta Histochem 109: 122 129 .

20. Thomas S, Prabhu R, Balasubramanian KA (2005) Surgical manipulation of the intestine and distant organ damage-protection by oral glutamine supplementation. Surgery 137: 48-55.

21. Demetriades H, Botsios D, Kazantzidou D, Sakkas L, Tsalis K, et al. (1999) Effect of early postoperative enteral feeding on the healing of colonic anastomoses in rats. Comparison of three different enteral diets. Eur Surg Res 31: $57-63$.

22. Gökpinar I, Gürleyik E, Pehlivan M, Ozcan O, Ozaydin I, et al. (2006) Early enteral and glutamine enriched enteral feeding ameliorates healing of colonic anastomosis: experimental study. Ulus Travma Acil Cerrahi Derg 12: 17-21.

23. da Costa MA, Campos AC, Coelho JC, de Barros AM, Matsumoto HM (2003) Oral glutamine and the healing of colonic anastomoses in rats. JPEN J Parenter Enteral Nutr 27: 182-185.

24. Graf W, Weiber S, Glimelius B, Jiborn H, Påhlman L, et al. (1992) Influence of 5 -fluorouracil and folinic acid on colonic healing: an experimental study in the rat. Br J Surg 79: 825-828.

25. Hillan K, Nordlinger B, Ballet F, Puts JP, Infante R (1988) The healing of colonic anastomoses after early intraperitoneal chemotherapy: an experimental study in rats. J Surg Res 44: 166-171.

26. Kanellos I, Kavouni A, Zaraboukas T, Odisseos C, Galovatsea K, et al. (1996) Influence of intraperitoneal 5-fluorouracil plus folinic acid on the healing of colonic anastomoses in rats. Eur Surg Res 28: 374-379.

27. Foitzik T, Kruschewski M, Kroesen AJ, Hotz HG, Eibl G, et al. (1999) Does glutamine reduce bacterial translocation? A study in two animal models with impaired gut barrier. Int J Colorectal Dis 14: 143-149.

28. Bergman I, Loxley R (1963) Two improved and simplified methods for the spectrophotometric determination of hydroxyproline. Anal Chem 35: 19611965.
29. Switzer BR, Summer GK (1971) Improved methods for hydroxyproline analysis in tissue hydrolyzates. Anal Biochem 39: 487-491.

30. Koçak I, Unlü C, Akçan Y, Yakin K (1999) Reduction of adhesion formation with cross-linked hyaluronic acid after peritoneal surgery in rats. Fertil Steril 72: 873-878.

31. De laco PA, Muzzupapa G, Bigon E, Pressato D, Donà M, et al. (2001) Efficacy of a hyaluronan derivative gel in postsurgical adhesion prevention in the presence of inadequate hemostasis. Surgery 130: 60-64.

32. Hananel N, Gordon PH (1995) Effect of 5-fluorouracil and leucovorin on the integrity of colonic anastomoses in the rat. Dis Colon Rectum 38: 886-890.

33. Brown GL, Curtsinger LJ, White M, Mitchell RO, Pietsch J, et al. (1988) Acceleration of tensile strength of incisions treated with EGF and TGF-beta. Ann Surg 208: 788-794.

34. van der Kolk BM, de Man BM, Wobbes T, Hendriks T (1999) Is early postoperative treatment with 5 -fluorouracil possible without affecting anastomotic strength in the intestine? Br J Cancer 79: 545-550.

35. Kuzu MA, Köksoy C, Kale T, Demirpençe E, Renda N (1998) Experimental study of the effect of preoperative 5-fluorouracil on the integrity of colonic anastomoses. Br J Surg 85: 236-239.

36. Rouse K, Nwokedi E, Woodliff JE, Epstein J, Klimberg VS (1995) Glutamine enhances selectivity of chemotherapy through changes in glutathione metabolism. Ann Surg 221: 420-426.

37. Sukhotnik I, Mogilner JG, Karry R, Shamian B, Lurie M, et al. (2009) Effect of oral glutamine on enterocyte turnover during methotrexate-induced mucositis in rats. Digestion 79: 5-13.

38. Cihan A, Oguz M, Acun Z, Uçan BH, Armutcu F, et al. (2004) Comparison of early postoperative enteral nutrients versus chow on colonic anastomotic healing in normal animals. Eur Surg Res 36: 112-115.

39. Kanellos I, Kavouni A, Zaraboukas T, Odisseos C, Galovatsea K, et al. (1996) Influence of intraperitoneal 5-fluorouracil plus folinic acid on the healing of colonic anastomoses in rats. Eur Surg Res 28: 374-379. 